\author{
Наталия ИВАЩУК ${ }^{1}$ \\ Жанна ПОПЛАВСКАЯ ${ }^{2}$ \\ Александр ИВАЩУК ${ }^{3}$
}

\title{
ПРОВЕРКА ТОЧНОСТИ ОЦЕНКИ СТАНДАРТНЫХ ОПЦИОНОВ НА АКЦИИ, ПОЛУЧЕННОЙ НА ОСНОВЕ МЕТОДА МОНТЕ-КАРЛО
}

\begin{abstract}
Статья посвящена алгоритму генерации случайной цены базового актива опциона, с помощью метода Монте-Карло. Представлена пошаговая схема оценки стоимости опциона, которая была применена к опциону, выставленному на акции трех украинских предприятий. Проведена оценка точности метода Монте-Карло, путем сравнивания полученных результатов с оценкой опционов по методу Блэка-Шоулза. Особое внимание в настоящей работе сконцентрировано на использовании математических методов и моделей в процессе оценивания опционов, которые могут использоваться в управлении различными видами рисков. Хозяйственные субъекты чаще всего используют опционы с целью ограничения ценового и валютного риска, по отношении к занятой либо будущей позиции на рынке спот. Такое управление рисками называют хеджированием позиций. Опционы могут также использоваться другими субъектами, в частности финансовыми институтами и инвесторами. Опционные стратегии особенно популярны среди финансовых инвесторов, которые составляют свои портфели из акций разных эмитентов. В этом случае используются опционы, выставленные на цены акций либо на фондовые индексы. Независимо от цели использования опционов, их цены являются затратами на построение стратегий управления риском. Поэтому каждый участник срочного рынка пытается минимизировать издержки связанные с управлением риском. В связи с этим, понимание процесса формирования цены опциона, способов его оценивания и возможностей выбора его параметров являются актуальными для тех финансовых менеджеров, которые применяют активный подход к управлению рисками на предприятии или в учреждении.
\end{abstract}

Ключевые слова: управление риском, деривативы, опционы, функция выплаты, опционная премия, хеджирование.

\footnotetext{
${ }^{1}$ Dr hab. inż. Natalia Iwaszczuk, AGH University of Science and Technology, Faculty of Management, Krakow (Д.э.н. Наталия Иващук, Факультет менеджмента, Горно-Металлургическая Академия).

2 Д.э.н., профессор Жанна Поплавская, Факультет менеджмента, Жешовская политехника им.И.Лука-севича, Жешов.

${ }^{3}$ Dr Oleksandr Ivashchuk, Cracow University of Technology, Institute of Economics, Sociology and Philosophy (К.э.н. Александр Иващук, Институт экономики, социологии и философии, Краковская политехника).
} 


\section{1. ВСТУПЛЕНИЕ}

Фондовые биржи становятся все более существенным элементом развития современной экономики. Главным предметом биржевого оборота являются акции, которые выполняют две важные функции: во-первых, источника финансирования новых инвестиций на предприятиях (в акционерных обществах); во-вторых, основного способа вложения капитала среди инвесторов. Если в первом случае, эмиссия акций (т.е. размещение бумаг на первичном фондовом рынке) не связана с каким-либо существенным риском, то во втором - инвесторы часто подвергаются риску (особенно при долгосрочных инвестициях), связанному с колебаниями цен акций на вторичном рынке и возможности полной утраты инвестированного капитала. Поэтому многие инвесторы опасаются риска, называемого инвестиционным либо риском портфеля ценных бумаг.

Управление инвестиционным риском может быть активным либо пассивным. Активные инвесторы часто изменяют состав инвестиционного портфеля, продавая и покупая акции (а также облигации и другие ценные бумаги) почти ежедневно. Пассивные же инвесторы стараются „страховать” свои инвестиции, используя различные инструменты финансового рынка. Одним из таких инструментов является опцион, который зачисляют к группе походных инструментов называемых деривативами (к ним относятся также: форвард, фьючерс и своп). Преимуществом этого дериватива, по сравнении с другими инструментами той же группы, есть то, что их использование не влечет за собой дополнительного риска, хотя связано с определенными издержками. Следует отметить, что в управлении инвестиционным риском безопасна только „длинная позиция” в опционном контракте, т.е. их приобретение.

Как уже упоминалось, использование опциона в управления риском связано с расходами на их покупку. В связи с этим появляются вопросы. Как велики могут быть эти расходы? Сколько стоит опцион с конкретными параметрами? Будет ли разработанная стратегия управления риском прибыльной? Чтобы ответить на эти вопросы, нужно самостоятельно оценить стоимость опциона (опционная премия), применяя различные математические методы и модели. В данной статье мы используем метод Монте-Карло - для вычисления цен опционов, выставленных на акции предприятий, который котируются на украинском фондовом рынке.

\section{2. ОПЦИОНЫ И ИХ ФУНКЦИЯ ВЫПЛАТЫ}

Опционный контракт - это соглашение, которое предоставляет покупателю опциона право к покупке (опцион типа call) либо продажи (опцион типа put) определенного количества базового инструмента, в согласованный между сторонами контракта промежуток/момент времени в будущем, по заранее согласованной цене, и обязывает продавца опциона к его реализации по требованию покупателя. В связи с этим, опционы можно поделить на опционы покупки (колл), которые дают право купить базовый инструмент у эмитента опциона, и опционы продажи (пут), подтверждающие право их владельца продать базовый инструмент эмитенту, который обязан его продать/купить по требованию владельца опциона.

Предметом опционного контракта чаще всего являются акции, но могут также быть: облигации, курсы валют, фондовые индексы, процентные ставки, товары 
и сырье, другие производные инструменты и т.п. Опционные контракты заключаются как на биржевом, так и на внебиржевом рынках. Основная их цель - защита хозяйственного субъекта от воздействия определенного вида риска. Такие субъекты часто называются хеджерами, а операции управления рисками (с целью ограничения либо ликвидации влияния неблагоприятных изменений цен на базовом рынке) хеджированием. Обычно второй стороной в этих контрактах выступают финансовые институты, принимающие на себя риск, за соответствующую оплату (опционную премию). Поскольку их целью является получение дохода от разницы цен базовых инструментов на срочном и кассовом рынках, то их называют спекулянтами.

Хеджирование можно также осуществлять при использовании других производных инструментов. Однако, в отличие от них, опцион, с одной стороны, обеспечивает защиту его владельца, а с другой - сохраняет для него возможность получения выгоды при благоприятном движении цены на спотовом рынке базового актива. Поскольку издержки связанные с управлением риском при помощи опцион-ных контрактов определяются величиной опционной премии (предполагая, что трансакционные издержки равны нулю), попробуем выяснить как она формируется.

Опционная премия - это сумма, которую должен заплатить покупатель опциона его продавцу (эмитенту) за возможность получения права на покупку/продажу базового инструмента. Опционная премия является доходом продавца опциона, в то время как потенциальный доход (конечная выплата, платеж) покупателя опциона зависит от разницы между рыночной ценой базового актива и ценой исполнения (страйковой ценой, strike price), либо наоборот, в зависимости от типа опциона (колл или пут). Следует отметить, что прибылью покупателя опциона будет разница между полученным доходом по опциону и уплаченной в момент его приобретения опционной премией. В свою очередь, прибыль эмитента - это разница между полученной опционной премией и выплатой по опциону, если такова будет. В большинстве случаев расчет между сторонами опционного контракта происходит не путем поставки базового актива, а в виде денежной суммы, рассчитанной согласно указанных выше принципам, а ее величину описывает функция выплаты каждого из этих деривативов.

Функцию выплаты (величину потенциального дохода, payoff) для держателя стандартного опциона можно записать следующим образом:

- для опционов с правом покупки (опцион колл): $C=\max \left[S_{T}-K, 0\right]$,

- для опционов с правом продажи (опцион пут): $\quad P=\max \left[K-S_{T}, 0\right]$, где $K$ - цена исполнения опциона,

$S_{T}$ - цена спот базового актива на момент реализации опциона.

Цена опциона, которой будет посвящена следующая часть данного исследования, является расходами держателя опциона. С целью вычисления конечного финансового результата на занятой позиции в опционном контракте, необходимо от полученного дохода по опциону (С либо Р) вычесть величину опционной премии. Однако возникает вопрос: как определить справедливую цену опциона? В течение последних 40 лет многие ученые пытались дать ответ на этот вопрос. Рассмотрим, какие подходы и методы были предложены до этого времени. 


\section{3. МОДЕЛИ И МЕТОДЫ ОЦЕНКИ ОПЦИОНОВ}

В теории финансов модели оценки опционов очень важны, поскольку многие корпоративные обязательства могут быть выражены в терминах опционов либо их комбинаций. В частности, Смит $(1976)^{4}$ обобщил основные достижения в теории ценообразования опционов, в условиях общего равновесия. Известная статья Блэка и Шоулза $(1973)^{5}$ представляет оценку стоимости опционов, которую они получили в условиях рыночного равновесия. Авторы предположили, что цена акции следует логнормальному распределению. Мертон ${ }^{6,7}$, а также Кокс и Росс $(1976)^{8}$ проанализировали структуру моделей оценки опционов и представили альтернативный подход к их оцениванию. По сути, они показали, что цена европейского опциона колл может быть получена путем дисконтирования ожидаемых сумм погашения опциона (цены его исполнения) по безрисковой процентной ставке. Распределение сумм погашения опциона может быть получено по распределению стоимости акций, на которые опцион выставлен. Таким образом, если распределение стоимости акций известно, то цена опциона может быть получена из интеграла. Однако такие интегралы, как правило, не имеют аналитического решения, поэтому в большинстве случаев опционы следует оценивать при помощи численных методов. Так, к примеру, Чен (1969) ${ }^{9}$ использовал метод численного интегрирования в своей диссертации об оценке варрантов (которые стали прототипами опционов), а позже Паркинсон $(1977)^{10}$ использовал этот подход для получения значений американских опционов с правом продажи базового актива ${ }^{11}$.

Вообще говоря, модели оценки опционов определяются факторами, которые влияют на их цену, и позволяют ее рассчитать, при тех или иных значениях факторов. Анализируя представленные научные работы, методы оценки опционов можно разделить на две основные группы:

А. Аналитические методы, то есть оценивание с помощью математически выведенных формул, которые позволяют сразу вычислить стоимость опциона. Примером применения метода из данной группы является формула БлэкаШоулза для оценки стандартных европейских опционов на акции, на которые не выплачиваются дивиденды. Однако, кроме стандартных опционов, существует целая гамма нестандартных (так называемых экзотических)

4 V.L. Smith, Experimental Economics: Induced Value Theory, „American Economic Review, Papers and Proceedings", (1976), s. 274-279.

5 F. Black, M. Scholes, The Pricing of Options and Corporate Liabilities, „The Journal of Political Economy" 81/3 (1973), s. 637-654.

${ }^{6}$ R.C. Merton, The Theory of Rational Option Pricing, ,Bell Journal of Mathematics and Management Science" 4/1 (1973), s. 141-183.

7 R.C. Merton, Option Pricing When Underlying Stock Returns are Discontinuous, „Journal of Financial Economics" 3 (1976), s. 125-144.

8 J.C. Cox, S.A. Ross, The valuation of options for alternative stochastic processes, „Journal of Financial Economics" 3 (1976), s. 145-166.

9 H. Chen, A Dynamic Programming Approach to the Valuation of Warrants, University of California, Berkeley, CA 1969 (Unpublished Ph.D. thesis).

${ }^{10}$ M. Parkinson, Option Pricing: The American Put, ,Forthcoming in the Journal of Business” (1977).

${ }^{11}$ P. Boyle, Options: a Monte Carlo Approach, „Journal of Financial Economics” 4 (1977), s. 323-338. 
опционов. К сожалению, аналитические формулы оценки найдены только для очень ограниченного их набора - бинарных опционов, простейших видов барьерных и азиатских, а также нескольких иных их разновидностей. Поэтому в большинстве случаев приходится использовать численные методы оценки этих деривативов.

В. Численные методы включают в себя: биномиальный метод, метод конечных разностей и метод Монте-Карло. Их преимуществом является то, что они позволяют оценить стоимость любых, даже самых сложных, с точки зрения функции выплаты, опционов, а также других деривативов. Однако, точность этих методов обычно не высока. Кроме того, они требуют большего количества вычислений и времени на получение результата.

Американские опционы являются более сложными в оценивании (по сравнению с европейскими аналогами), поскольку их можно реализовать в любое время, на протяжении срока их действия. К оценке именно таких опционов многие ученые ${ }^{12,13,14,15}$ применяли метод Монте-Карло. В этой статье мы однако сконцентрируемся на применении этого метода к оценке европейских стандартных опционов, выставленных на акции избранных предприятий, с целью сравнения его точности с наиболее известной и распространенной моделью Блэка-Шоулза. Проведенный исследования будут базой для оценивания, при помощи метода Монте-Карло, некоторых видов экзотических опционов.

\section{4. ОЦЕНКА ЕВРОПЕЙСКИХ ОПЦИОНОВ МЕТОДОМ МОНТЕ-КАРЛО}

Существует ряд научных работ, описывающих применение метода Монте-Карло, в частности, в работе ${ }^{16}$ исследуется применение метода Монте-Карло и квазиМонте-Карло в финансах. Ее авторы рассматривают два отдельных способа применения этого метода: во-первых, метод Монте-Карло применяется для вычисления интегралов, связанных с оценкой опционов европейского типа исполнения; во-вторых, адаптивный метод Монте-Карло применяется для разностной аппроксимации частных дифференциальных уравнений, сформирован-ных классом финансовых задач. В статье также проанализировано преимущества использования метода Монте-Карло, по сравнению с другими методами оценки опционов. Другая работа

12 L.C.G. Rogers, Monte Carlo Valuation of American Options, University of Bath, http://www. skokholm. co.uk/wp-content/uploads/2013/02/mcamer.pdf.

${ }^{13}$ C. Yang, S. Tompaidis, Pricing American-Style Options by Monte Carlo Simulation: Alternatives to Ordinary Least Squares, University of Texas at Austin, http://faculty.mccombs.utexas. edu/stathis. tompaidis/code/LSM/lsm_paper.pdf

${ }^{14}$ P. Boyle, M. Broadie, P. Glasserman, Monte Carlo Methods for Security Pricing, ,Journal of Economic Dynamics and Control" 21 (1997), s. 1267-1321.

15 C. Pizzi, P. Pellizzari, Monte Carlo Pricing of American Options Using Nonparametric Regression, Finance. Economics working paper archive at WUSTL 2002, s. 1-15. http://down.cenet.org.cn/upfile/54/ 20056812464185.pdf

16 Y. Lai, J. Spanier, Applications of Monte Carlo/Quasi-Monte Carlo Methods in Finance: Option Pricing, Claremont Graduate University. - http://www.smartquant.com/ references/MonteCarlo/mc6.pdf 
в этой тематике - С. Майданова ${ }^{17}$, посвящена сравнению производительности и простоты использования генераторов случайных чисел, доступных в некоторых промышленных библиотеках. Как основу для опционного ценообразования, автор использует известную модель Блэка-Шоулза, однако отмечает, что метод МонтеКарло является более простым и удобным инстру-ментом для оценки деривативов, в условиях реального рынка. Кроме того, этот метод характеризуется гибкостью, то есть его можно легко модифицировать для различных процессов, влияющих на основные доходы от акций. Более того, метод Монте-Карло может быть использован как дополнение к упомянутым выше методам, поскольку имеет явные преимущества в некоторых особых ситуациях - например, когда основной доход от акций имеет вид скачкообразного процесса. По сути, метод использует тот факт, что распределение цен акций определяется процессом генерации будущих изменений цен на акции. Этот процесс может быть смоделирован при помощи компьютера, создавая тем самым серию траекторий котировок акций, которая будет определять набор цен для срочных акций, используемых для получения оценки стоимости опционов. Кроме того, стандартное отклонение оценки может быть получено тогда же, когда будет установлена точность результатов.

\section{1. Основной принцип применения метода к оценке опционов}

Метод Монте-Карло заключается в оценке математического ожидания выплаты, которую в будущем может сгенерировать опцион для его владельца, путем многократного генерирования возможных ценовых путей движения акции. Суть метода можно продемонстрировать на примере игральной кости. Представим себе, что перед нами стоит задача определения математического ожидания (проще говоря - среднего значения) количества очков, выпадающих на кубике. Каким образом можно решить эту задачу? Можно аналитически, т.е. путем суммирования значений на гранях кубика, умноженных на вероятность выпадания соответствующей грани, то есть

$$
1 / 6 \times 1+1 / 6 \times 2+\cdots+1 / 6 \times 6=3.5
$$

(если кубик является совершенным, то вероятность выпадания любой грани равна 1/6). Эту задачу можно тоже решить численно, с помощью метода Монте-Карло. Для этого нужно бросить кубик, например, 1000000 раз и рассчитать среднее значение числа очков, выпавших в результате этих экспериментов. Полученное значение может быть равно, например, 3,497 или 3,504, то есть оно будет очень близким к реальному математическому ожиданию, но некоторая погрешность все же останется. При этом, чем больше раз будет брошен кубик, тем точнее получится результат.

Каждый отдельный бросок кубика называется итерацией. Полный набор итераций образует симуляцию Монте-Карло. Оценка опциона методом Монте-Карло выглядит подобным образом: необходимо рассчитать, какую выплату (рауoff) в среднем сгенерирует опцион на дату окончания его действия.

${ }^{17}$ S. Maidanov, Monte Carlo European Option Pricing Implementation Using Various Industry Library Solutions, https://software.intel.com/sites/products/collateral/hpc/mkl/ monte-carlo-optionspricing.pdf 


\section{2. Математические основы применения метода к оценке европейских опционов}

Впервые идея применения метода Монте-Карло для оценки европейских опционов на акции была предложена П. Бойлем в 1976 году. Результаты его исследований были опубликованы в работе „Опционы: подход Монте-Карло”18. Опишем основные идеи Бойля относительно применения этого метода, с целью вычисления цены стандартного опциона. Для этого введем следующие обозначения:

$S_{t}$ - цена акции в момент времени $t$,

$r$ - безрисковая процентная ставка,

$\sigma-$ волатильность акции,

$D_{t}$ - дивиденды, выплачиваемые по акции в момент времени $t$,

$E$ - цена исполнения опциона,

$T$ - срок действия опциона.

В том же году Кокс и Росс ${ }^{19}$ показали, что предположение отсутствия риска (безрисковости) можно использовать для получения решения проблемы оценки опционов. Это означает, что равновесная ставка доходности активов и, в частности, ставка дивиденд по обыкновенных акциях, может быть равна безрисковой процентной ставке (т.е. ставке предложения капитала на межбанковском рынке). Из этого предположения можно получить ожидаемую доходность акций

$$
E\left(S_{T} / S_{t}\right)=\exp (r[T-t])
$$

Кроме того, предполагается, что соотношение $S_{t+1} / S_{t}$ имеет логарифмическинормальное распределение со значением, равным $\exp (r)$. Чтобы связать $r$ с параметрами нормального распределения, которое следует из $\log \left[S_{t+1} / S_{t}\right]$, удобно записать

$$
E\left(\frac{S_{T}}{S_{t}}\right)=\exp (r)=\exp \left[\left(r-\sigma^{2} / 2\right)+\sigma^{2} / 2\right]
$$

Отсюда, ожидаемое значение $\log \left[S_{t+1} / S_{t}\right]$ равно $\left(r-\sigma^{2} / 2\right)$. Используя свойства логнормального распределения, можно сгенерировать распределение цен акций путем генерирования случайных величин

$$
S_{t+1}=S_{t} \exp \left[r-\sigma^{2} / 2+\sigma \tilde{x}\right]
$$

где $\tilde{x}$ - нормально распределенная случайная величина, с нулевым средним и единичной дисперсией.

Чтобы провести симуляцию метода, необходимо сгенерировать величину $S_{t+1}$. Если ее значение будет больше, чем значение дивидендной выплаты $D_{t+1}$, то разница $\left(S_{t+1}-D_{t+1}\right)$ используется в качестве начального значения следующего временного периода, и процедура продолжается до тех пор, пока не будет получено значение $S_{T}$. Если же на определенном временном промежутке $S_{t+m}(m=1,2, \ldots,(T-t-1))$ будет меньше или равно дивидендам $D_{t+m}$, то процесс остановится. В этом случае следующая симуляция метода начинается снова, с момента времени $t$. Серия

\footnotetext{
${ }^{18}$ P. Boyle, op. cit.

19 J.C. Cox, S.A. Ross, op. cit.
} 
симуляций продолжается и в конечном итоге можно получить искомое значение $\operatorname{Max}\left[S_{T}-E, 0\right]$.

Поскольку первоначальная идея применения метода Монте-Карло касалась оценки опционов, выставленных на акции, по которым выплачиваются дивиденды, то в данной работе будет рассмотрен процесс оценивания именно таких походных финансовых инструментов.

\section{3. Генерирование случайной цены акции}

В случае с кубиком, мы осуществляли бросок, ждали некоторое время, пока кубик перестанет крутиться и остановится, и записывали количество выпавших очков. Каким образом происходит „бросок” в случае акции? Генерирование случайного значения будущей цены акции производится с помощью следующей формулы ${ }^{20}$ :

$$
S_{t}=S_{0} \times \exp \left(\left[\mu-\frac{1}{2} \sigma^{2}\right] t+\sigma \sqrt{t} \times N_{0,1}\right),
$$

где $t$ - будущий момент времени, в годах ( $t=0$ - текущий момент времени, $t=1-$ момент времени через 1 год),

$S_{t}$ - цена акции в будущий момент времени $t$,

$S_{0}$ - текущая цена акции,

$\mu$ - математическое ожидание доходности акции, выраженное в \% годовых (то, что принято называть „ожидаемой доходностью” акции),

$\sigma$ - стандартное отклонение доходности акции, выраженное в \% годовых (эту величину называют „волатильностью”),

$\exp (\mathrm{x})$ - функция экспоненты,

$N_{0,1}$ - случайная величина, имеющая стандартное нормальное распределение (с математическим ожиданием равным 0 и стандартным отклонением равным 1).

Ту часть формулы, которая находится ввнутри ехр, можно считать случайной доходностью акции (но не арифметической, а „логарифмической”, т.е. такой, которая рассчитывается через $\left.\ln \left(P_{1} / P_{0}\right)\right)$. Данная формула отвечает общепринятой модели движения цены акции, которая легла в основу модели Блека-Шоулза и многих других моделей оценки деривативов, и является одной из основ современной финансовой математики. Математически, данная формула - это решение стохастического дифференциального уравнения, описывающего изменения цены акции ${ }^{21}$.

Следует отметить, что указанная формула является подходящей моделью только для описания движения цен на акции. Однако она не применима для других базовых активов, таких к примеру, как облигации, товары, процентные ставки и др. Для них были созданы иные модели. В настоящей работе будет произведена оценка опционов, выставленных исключительно на акции.

Сгенерировать случайную будущую цену акции можно с помощью известных языков программирования (C ++, C \#, VBA и т.д.) либо с использованием готовых функций (напр. в Excel). Можно также использовать такие специальные программы, как например, калькулятор стандартных либо экзотических опционов.

\footnotetext{
${ }_{20}$ М. Глухов, Оиенка опиионов методом Монте-Карло, „Futures\&Options” 4 (2009), s. 38-43.

${ }^{21}$ М. Глухов, op. cit.
} 


\section{5. РЕАЛИЗАЦИЯ МЕТОДА НА ПРИМЕРЕ ОПЦИОНОВ НА АКЦИИ УКРАИНСКИХ ПРЕДПРИЯТИЙ}

Процесс оценивания опциона, с использованием метода Монте-Карло, схематично можно представить в виде рис. 1. К примеру, оценка стандартного европейского опциона типа колл, выставленного на акции предприятий, будет осуществляться в пять этапов:

I. Генерирование случайной будущей цены акции на дату исполнения опциона, с использованием безрисковой процентной ставки в качестве ожидаемой доходности акции.

II. Расчет выплаты по данному опциону, при заданной цене акции. Шаги 1 и 2 образуют одну итерацию. Результатом итерации будет значение случайной величины - значения выплаты по опциону.

III. Шаги 1 и 2 повторяются много раз, например, 1000.

IV. Из полученных значений вычисляется среднее значение выплаты по опциону.

V. Среднее значение дисконтируется по безрисковой ставке, что дает в результате оценку справедливой цены опциона (т.е. опционной премии).

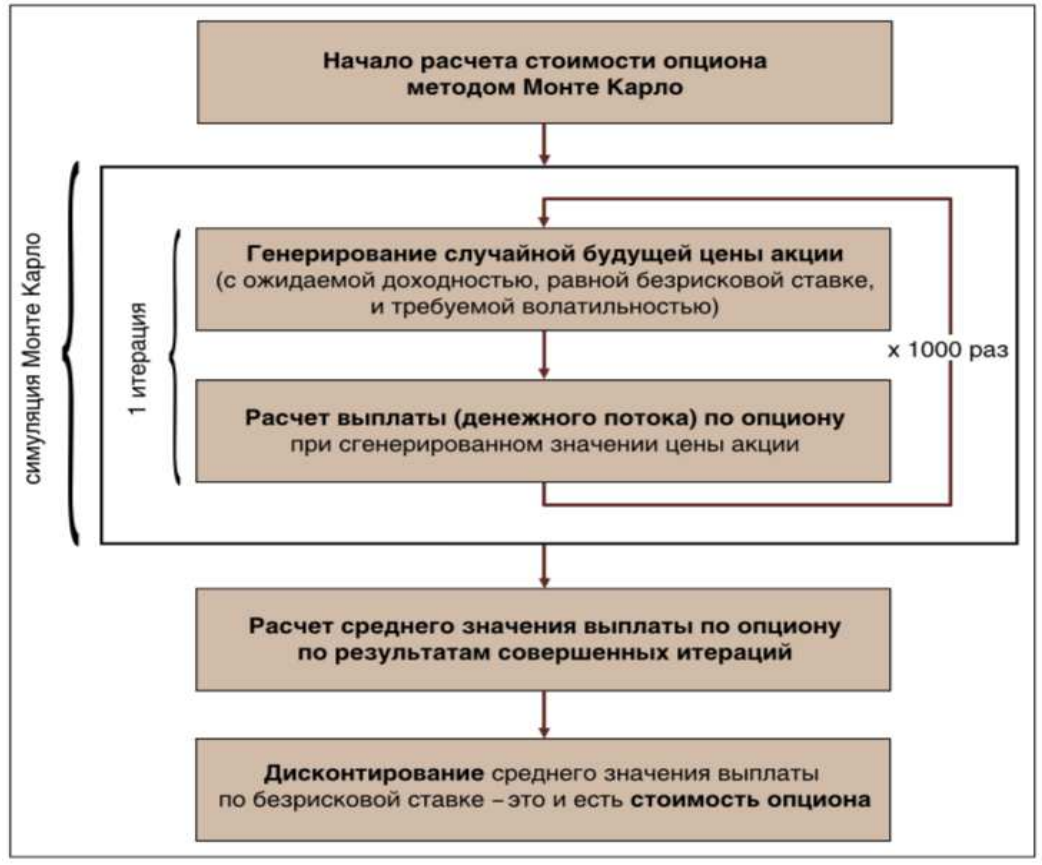

Рис. 1. Схема оценки опциона методом Монте-Карло

Источник ${ }^{22}$.

Таким образом, в соответствии с методом Монте-Карло, стоимость опциона - это дисконтированное значение математического ожидания выплаты по опциону,

${ }^{22}$ М. Глухов, op. cit., s. 39. 
рассчитанное при ожидаемой доходности акции, равной безрисковой процентной ставке. С помощью необходимых программных средств, осуществляется генерирование 1000 случайных цен и рассчитываются соответствующие выплаты по опциону. В результате проведения 1000 итераций получается среднее значение выплаты по опциону, а далее проводится его дисконтирование по безрисковой процентной ставке. При проведении 10000 итераций результат будет более точным. Точность можно повысить производя, на пример, 100000 итераций. Вообще говоря, чем больше итераций осуществить, в рамках симуляции Монте-Карло, тем ближе полученный результат будет к истинной стоимости опциона. С ростом числа итераций, метод Монте-Карло должен дать результат, идентичный в 100\% итогу, полученному с помощью формулы Блэка-Шоулза.

Рассмотрим конкретное применение описанной схемы оценки опциона, на примере трех украинских предприятий: ОАО „Галичфарм”, ОАО „Запорожсталь” и ОАО „Львовоблэнерго”. Данные для оценки опциона на акции ОАО „Галичфарм” приведены в таблице 1 .

В результате проведения 1000 итераций (табл. 2), получено среднее значение выплаты по опциону, равное 10,6321. Продисконтировав это значение по безрисковой процентной ставке, получено 10,0130. Результат достаточно близок к цене опциона $(10,0446)$, полученной с помощью калькулятора для формулы БлэкаШоулза ${ }^{23}$. Зависимость точности оценки стоимости опциона по методу Монте-Карло от количества итераций можно продемонстрировать с помощью графика (Рис. 2).

Табл. 1. Данные для оценки опциона на акции ОАО „Галичфарм”

\begin{tabular}{|l|r|}
\hline Страйк опциона & 100 \\
\hline Срок действия опциона, лет & 1 \\
\hline Цена акции & 92 \\
\hline Волатильность акции & $30,00 \%$ \\
\hline Безрисковая процентная ставка & $6,00 \%$ \\
\hline Стоимость опциона по формуле Блэка-Шоулза & 10,0446 \\
\hline
\end{tabular}

Источник: собственные вычисления на основе данных ${ }^{24}$.

Данные для оценки опциона на акции ОАО „Запорожсталь” приведены в таблице 3. В результате проведения 1000 итераций (табл. 4) получено среднее значение выплаты по опциону, равное 0,0008. Продисконтировав это значение по безрисковой процентной ставке, получено 0,0007. Результат равен значению 0,0007, полученному с помощью калькулятора для формулы Блэка-Шоулза 25 . Зависимость точности оценки стоимости опциона по методу Монте-Карло от количества итераций можно продемонстрировать с помощью графика (Рис. 3).

${ }^{23} \mathrm{http} / / / \mathrm{www} \cdot$ kalkulaator.ee/?lang=2\&page=29.

${ }^{24} \mathrm{http}: / / \mathrm{www}$. investfunds.ua/markets/stocks/.

${ }^{25} \mathrm{http} / / /$ www.kalkulaator.ee/?lang=2\&page $=29$. 
Табл. 2. Результаты вычисления стоимости опциона на акции ОАО „Галичфарм”

\begin{tabular}{|c|c|c|c|}
\hline $\begin{array}{c}\text { Номер } \\
\text { итерации }\end{array}$ & $\begin{array}{c}\text { Случайная цена акции } \\
\text { в день окончания действия } \\
\text { опциона }\end{array}$ & $\begin{array}{c}\text { Выплата по } \\
\text { опциоу }\end{array}$ & $\begin{array}{c}\text { Среднее } \\
\text { дисонтированное } \\
\text { значение }\end{array}$ \\
\hline 1 & 93,3707 & 0,0000 & 0,0000 \\
\hline 2 & 81,7809 & 0,0000 & 0,0000 \\
\hline 3 & 87,1767 & 0,0000 & 0,0000 \\
\hline 4 & 88,2827 & 0,0000 & 0,0000 \\
\hline 5 & 75,5210 & 0,0000 & 0,0000 \\
\hline 6 & 125,5072 & 25,5072 & 4,0036 \\
\hline 7 & 85,0806 & 0,0000 & 3,4317 \\
\hline 8 & 123,5477 & 23,5477 & 5,7748 \\
\hline 9 & 79,9251 & 0,0000 & 5,1331 \\
\hline 10 & 122,5482 & 22,5482 & 6,7433 \\
\hline$\ldots$ & $\ldots$ & $\ldots$ & $\ldots$ \\
\hline 1000 & 84,28404469 & 10,6321 & 10,0130 \\
\hline
\end{tabular}

Источник: собственные вычисления на основе данных ${ }^{26}$.

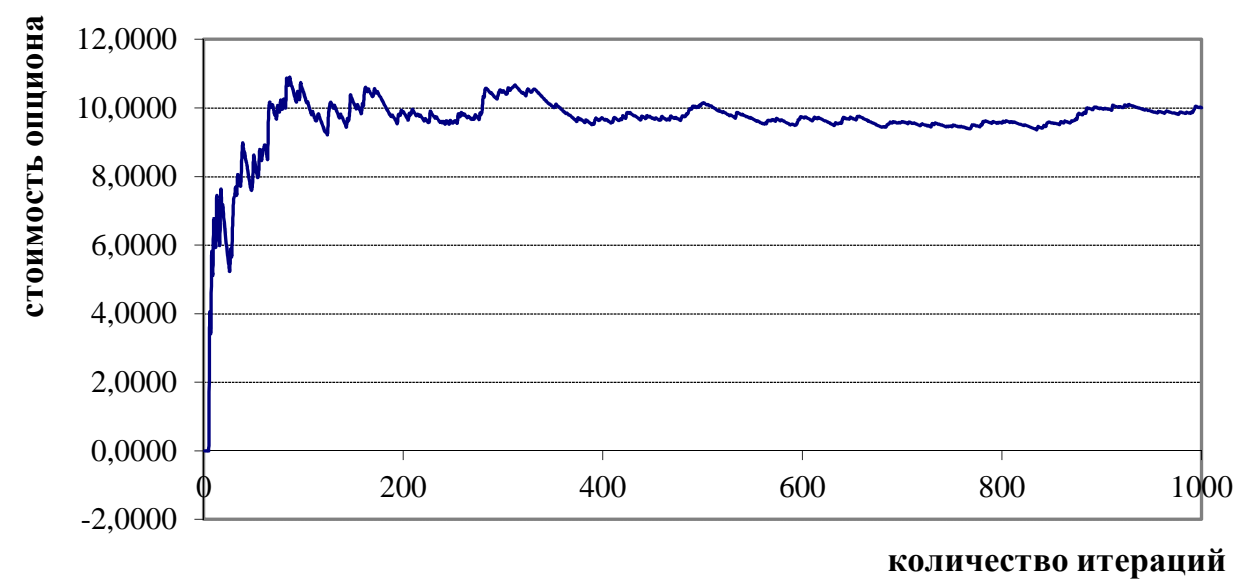

Рис. 2. Увеличение точности оценки стоимости опциона на акции ОАО „Галичфарм”, с увеличением количества итераций

Источник: собственные вычисления на основе данных ${ }^{27}$.

26 http://www.investfunds.ua/markets/stocks/.

${ }^{27}$ http://www.investfunds.ua/markets/stocks/. 
Табл. 3. Данные для оценки опциона на акции ОАО „Запорожсталь”

\begin{tabular}{|l|r|}
\hline Страйк опциона & 0,58 \\
\hline Срок действия опциона, лет & 1 \\
\hline Цена акции & 0,29 \\
\hline Волатильность акции & $30,00 \%$ \\
\hline Безрисковая процентная ставка & $6,00 \%$ \\
\hline Стоимость опциона по формуле Блэка-Шоулза & 0,0007 \\
\hline
\end{tabular}

Источник: собственные вычисления на основе данных ${ }^{28}$.

Табл. 4. Результаты вычисления стоимости опциона на акции ОАО „Запорожсталь”

\begin{tabular}{|c|c|c|c|}
\hline $\begin{array}{c}\text { Номер } \\
\text { итерации }\end{array}$ & $\begin{array}{c}\text { Случайная цена акции } \\
\text { вень окончания действия } \\
\text { опциона }\end{array}$ & $\begin{array}{c}\text { Выплата по } \\
\text { опциону }\end{array}$ & $\begin{array}{c}\text { Среднее } \\
\text { дисонтированное } \\
\text { значение }\end{array}$ \\
\hline 1 & 0,3612 & 0,0000 & 0,0000 \\
\hline 2 & 0,2771 & 0,0000 & 0,0000 \\
\hline 3 & 0,3465 & 0,0000 & 0,0000 \\
\hline 4 & 0,3358 & 0,0000 & 0,0000 \\
\hline 5 & 0,1812 & 0,0000 & 0,0000 \\
\hline 6 & 0,2750 & 0,0000 & 0,0000 \\
\hline 7 & 0,2486 & 0,0000 & 0,0000 \\
\hline 8 & 0,3139 & 0,0000 & 0,0000 \\
\hline 9 & 0,4255 & 0,0000 & 0,0000 \\
\hline 10 & 0,4280 & 0,0000 & 0,0000 \\
\hline$\ldots$ & $\ldots$ & $\ldots$ & $\ldots$ \\
\hline 1000 & 0,2115 & 0,0008 & 0,0007 \\
\hline
\end{tabular}

Источник: собственные вычисления на основе данных ${ }^{29}$.

Данные для оценки опциона на акции ОАО „Львовоблэнерго” приведены в таблице 5. В результате проведения 1000 итераций (табл. 6) получено среднее значение выплаты по опциону, равное 0,0487. Продисконтировав это значение по безрисковой процентной ставке, получено 0,0458. Результат близок к значению 0,0446, полученному с помощью калькулятора для формулы Блэка-Шоулза ${ }^{30}$. Зависимость точности оценки стоимости опциона по методу Монте-Карло от количества итераций можно продемонстрировать с помощью графика (Рис. 4).

28 http://www.investfunds.ua/markets/stocks/.

${ }^{29} \mathrm{http} / / / \mathrm{www}$.investfunds.ua/markets/stocks/.

${ }^{30} \mathrm{http} / / /$ www.kalkulaator.ee/?lang=2\&page $=29$. 


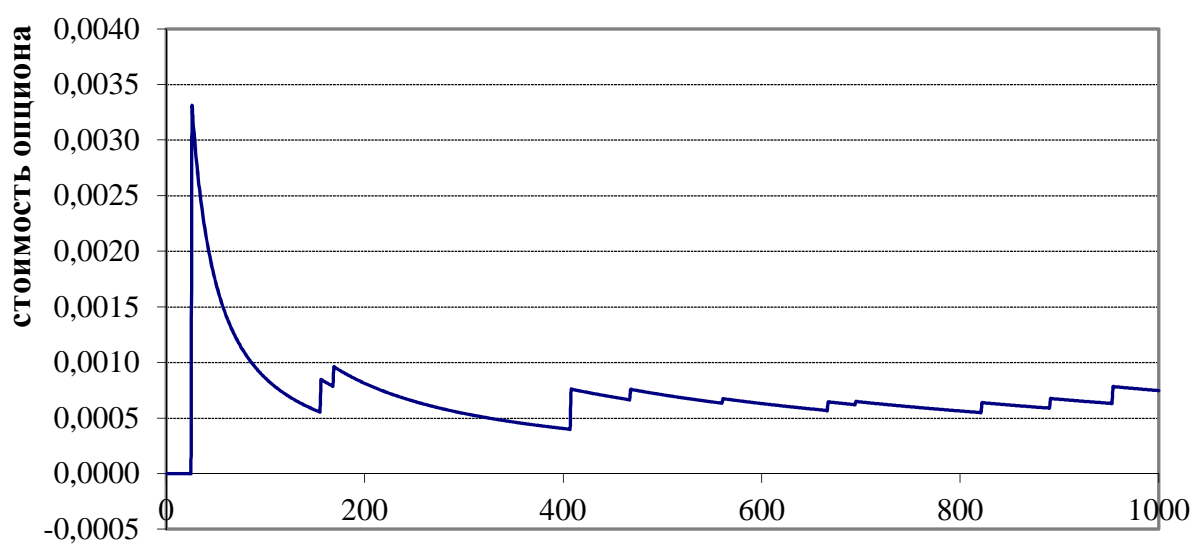

количество итераций

Рис. 3. Увеличение точности оценки стоимости опциона на акции ОАО „Запорожсталь”, с увеличением количества итераций

Источник: собственные вычисления на основе данных ${ }^{31}$.

Табл. 5. Данные для оценки опциона на акции ОАО „Львовоблэнерго”

\begin{tabular}{|l|c|}
\hline Страйк опциона & 1,50 \\
\hline Срок действия опциона, лет & 1 \\
\hline Цена акции & 1,11 \\
\hline Волатильность акции & $30,00 \%$ \\
\hline Безрисковая процентная ставка & $6,00 \%$ \\
\hline Стоимость опциона по формуле Блэка-Шоулза & 0,0446 \\
\hline
\end{tabular}

Источник: собственные вычисления на основе данных ${ }^{32}$.

Подводя итоги проведенных исследований, к преимуществам метода МонтеКарло можно отнести следующие: определенность позиции хеджера (стоимость опциона - это сумма денег, которую нужно заплатить, чтобы приобрести опцион); универсальность метода (он позволяет оценивать практически любые опционы); простота реализации (т.е. возможность реализации оценки опциона методом МонтеКарло с помощью известных программных продуктов и пакетов математических программ).

31 http://www.investfunds.ua/markets/stocks/.

${ }^{32} \mathrm{http}: / / \mathrm{www}$. investfunds.ua/markets/stocks/. 
Табл. 6. Результаты вычисления стоимости опциона на акции ОАО „Львовоблэнерго”

\begin{tabular}{|c|c|c|c|}
\hline $\begin{array}{c}\text { Номер } \\
\text { итерации }\end{array}$ & $\begin{array}{c}\text { Случайная цена акции } \\
\text { в день окончания } \\
\text { действия опциона }\end{array}$ & $\begin{array}{c}\text { Выплата по } \\
\text { опциону }\end{array}$ & $\begin{array}{c}\text { Среднее } \\
\text { дисонтированное } \\
\text { значение }\end{array}$ \\
\hline 1 & 1,6392 & 0,1392 & 0,1311 \\
\hline 2 & 1,1294 & 0,0000 & 0,0655 \\
\hline 3 & 0,8278 & 0,0000 & 0,0437 \\
\hline 4 & 0,9695 & 0,0000 & 0,0328 \\
\hline 5 & 1,0825 & 0,0000 & 0,0262 \\
\hline 6 & 0,6826 & 0,0000 & 0,0218 \\
\hline 7 & 0,8804 & 0,0000 & 0,0187 \\
\hline 8 & 1,4176 & 0,0000 & 0,0164 \\
\hline 9 & 1,3057 & 0,0000 & 0,0146 \\
\hline 10 & 1,0485 & 0,0000 & 0,0131 \\
\hline$\ldots$ & $\ldots$ & & $\ldots$ \\
\hline 1000 & 0,6532 & 0,0487 & 0,0458 \\
\hline
\end{tabular}

Источник: собственные вычисления на основе данных ${ }^{33}$.

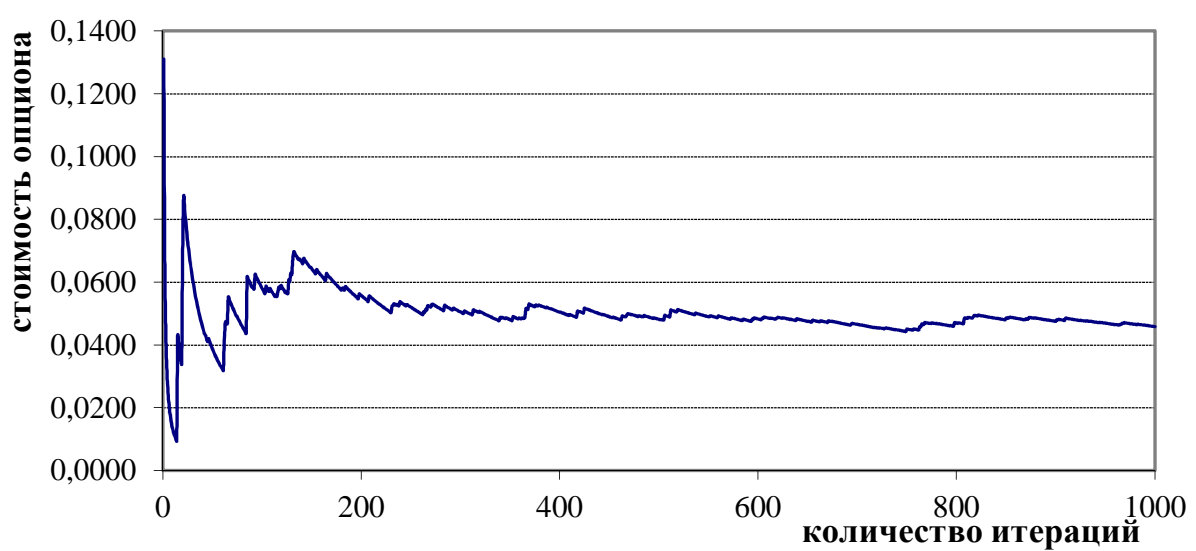

Рис. 4. Увеличение точности оценки стоимости опциона на акции ОАО „Львовоблэнерго”, с увеличением количества итераций

Источник: собственные вычисления на основе данных ${ }^{34}$

Существуют тоже недостатки этого метода, к которым можно зачислить то, что метод плохо подходит для оценки американских опционов и других опционов с возможностью досрочного погашения, а также то, что для достижения высокой точности, необходимо выполнить большое количество итераций, а это в свою очередь требует больших затрат времени, по сравнению с другими методами.

$33 \mathrm{http}: / /$ www.investfunds.ua/markets/stocks/

${ }^{34} \mathrm{http} / / / \mathrm{www}$. investfunds.ua/markets/stocks/ 


\section{6. ЗАКЛЮЧЕНИЕ}

В работе описано применение метода Монте-Карло к вычислению определенного интеграла и применение этого же метода к оценке европейских опционов. Метод простой и эластичны в том смысле, что он может быть легко модифицирован для различных процессов, регулирующих основные доходы, получаемые от акций. Кроме того, он имеет явные преимущества в некоторых особых ситуациях например, когда основной доход от акций имеет скачкообразный характер. Метод использует тот факт, что распределение цен акций определяется процессом генерации будущих движений цен на акции. Кроме того, метод нашел применение для вычисления будущей стоимости колл-опциона и ожидаемой доходности на примере акций украинских предприятий. Для каждого вычисления, рассчитанное численное значение сравнивается со значениями, полученными аналитически по формуле Блэка-Шоулза. На основе такого сравнения можно сделать вывод, что результат, полученный при использовании метода Монте-Карло, является достаточно точным, поскольку погрешность стремится к нулю, с увеличением количества проведенных итераций при генерировании случайной цены. Следовательно, в тех случаях, когда к оценке опциона нельзя применить модели Блэка-Шоулза, можно использовать описанный выше метод Монте-Карло, который дает сравнительно точный результат.

Современная экономическая теория как на микро-, так и на макроуровне, не может обойтись без математических методов и моделей. Использование математики в экономике позволяет, прежде всего, выделить и формально описать наиболее существенные связи между переменными и объектами в экономической системе. Кроме того, с четко сформулированных исходных данных и соотношений методом дедукции можно получать выводы, адекватные изучаемому объекту. Методы математики и статистики позволяют также индуктивным путем получать новые знания об объекте: оценивать форму и параметры зависимостей между его переменными, которые больше всего соответствуют имеющимся наблюдениям. И, наконец, использование математического языка позволяет точно и компактно излагать основный положения экономической теории, формулировать ее понятия и выводы.

\section{ЛИТЕРАТУРА}

[1] Black F., Scholes M., The Pricing of Options and Corporate Liabilities, „The Journal of Political Economy" 81/3 (1973), s. 637-654.

[2] Boyle P., Options: a Monte Carlo Approach, „Journal of Financial Economics” 4 (1977), s. 323-338.

[3] Boyle P., Broadie M., Glasserman P., Monte Carlo Methods for Security Pricing, ,Journal of Economic Dynamics and Control" 21 (1997), s. 1267-1321.

[4] Chen H., A Dynamic Programming Approach to the Valuation of Warrants, University of California, Berkeley, CA 1969 (Unpublished Ph.D. thesis).

[5] Cox J.C., Ross S.A., The valuation of options for alternative stochastic processes, ,Journal of Financial Economics" 3 (1976), s. 145-166. 
[6] Lai Y., Spanier J., Applications of Monte Carlo/Quasi-Monte Carlo Methods in Finance: Option Pricing, Claremont Graduate University, http://www.smartquant.com/references/ MonteCarlo/mc6.pdf.

[7] Maidanov S., Monte Carlo European Option Pricing Implementation Using Various Industry Library Solutions, https://software.intel.com/sites/products/collateral/hpc/mkl/ monte-carlo-options-pricing.pdf.

[8] Merton R.C., The Theory of Rational Option Pricing, „Bell Journal of Mathematics and Management Science” 4/1 (1973), s. 141-183.

[9] Merton R.C., Option Pricing When Underlying Stock Returns are Discontinuous, ,Journal of Financial Economics" 3 (1976), s. 125-144.

[10] Parkinson M., Option Pricing: The American Put, „Forthcoming in the Journal of Business" (1977).

[11] Pizzi C., Pellizzari P., Monte Carlo Pricing of American Options Using Nonparametric Regression, Finance. Economics working paper archive at WUSTL 2002, s. 1-15. http://down.cenet.org.cn/upfile/54/20056812464185.pdf.

[12] Rogers L.C.G., Monte Carlo Valuation of American Options, University of Bath, http://www.skokholm.co.uk/wp-content/uploads/2013/02/mcamer.pdf.

[13] Smith V.L., Experimental Economics: Induced Value Theory, „American Economic Review, Papers and Proceedings", (1976), s. 274-279.

[14] Yang C., Tompaidis S., Pricing American-Style Options by Monte Carlo Simulation: Alternatives to Ordinary Least Squares, University of Texas at Austin, http://faculty.mccombs.utexas.edu/stathis.tompaidis/code/LSM/lsm_paper.pdf.

[15] Глухов М., Оиеека опциионов методом Монте-Карло, „Futures\&Options” 4 (2009), s. 38-43.

[16] http://www.investfunds.ua/markets/stocks/ - котирования акций украинской биржи.

[17] http://www.kalkulaator.ee/?lang=2\&page=29 - финансовый калькулятор вычисления стоимости европейского опциона по формуле Блэка-Шоулза.

\section{CHECK THE ACCURACY OF STANDARD STOCK OPTIONS VALUATION RECEIVED ON THE BASIS OF MONTE CARLO METHOD}

The article is devoted to the algorithm for generating the random price of the option underlying asset by using the Monte Carlo method. The scheme of estimation of option value is presented in the article and is implemented on the example of three Ukrainian enterprises shares. The accuracy of the Monte Carlo method is considered, comparing the obtained results with the evaluation of options for the Black-Scholes method. In this paper, special attention has focused on the use of mathematical methods and models in the evaluation process of options that could be used to manage different types of risks. The economic entities often use options to limit price and currency risk in relation to the present or future position in the spot market. That risk management called hedging of positions. Options can be used by financial institutions and investors, too. Option strategies are especially popular among financial investors, who make up their portfolios of shares of different issuers. In this case, there are used the options in which the stock price or stock index is the underlying asset. Whatever the purpose of the use of options, their prices are the costs of risk management strategies building. Therefore, every participant in the derivatives market is trying to minimize the costs associated with risk management. In this regard, understanding the process of pricing options, ways of its 
evaluation and choice of its parameters are relevant to the financial managers who take a proactive approach to risk management at the enterprise or institution.

Keywords: risk management, derivatives, options, payment function, the option premium, hedging.

\section{DOKŁADNOŚĆ STANDARDOWEJ WYCENY OPCJI NA AKCJE OTRZYMANEJ NA PODSTAWIE METODY MONTE CARLO}

Artykuł został poświęcony algorytmowi generacji losowej ceny instrumentu bazowego opcji, przy zastosowaniu metody Monte Carlo. Zaprezentowano też schemat szacowania ceny opcji, który został zastosowany w odniesieniu do opcji wystawionych na akcje trzech ukraińskich spółek. Sprawdzono dokładność metody Monte Carlo poprzez porównanie otrzymanych wyników z cenami opcji, obliczonymi zgodnie z metodą Blacka-Scholesa. Szczególną uwagę w pracy zwrócono na zastosowanie matematycznych metod i modeli do szacowania cen opcji, które mogą być wykorzystywane w zarządzaniu różnymi rodzajami ryzyka. Podmioty gospodarcze często korzystają z opcji, aby ograniczyć ryzyko walutowe i ryzyko cenowe, w stosunku do zajętej lub przyszłej pozycji na rynku kasowym. Takie zarządzanie ryzykiem przyjęto nazywać hedżowaniem pozycji. Opcje mogą być również wykorzystywane przez inne podmioty, w tym przez instytucje finansowe i inwestorów. Strategie opcyjne są szczególnie popularne wśród inwestorów instytucjonalnych, którzy tworzą swoje portfele z akcji różnych emitentów. W tym przypadku, wykorzystywane są opcje wystawione na ceny akcji lub indeksy giełdowe. Jednak, niezależnie od celu wykorzystywania opcji, ich ceny stanowią koszt budowy strategii zabezpieczających. Dlatego każdy uczestnik rynku terminowego próbuje zminimalizować koszty związane z zarządzaniem ryzykiem. W związku z powyższym, zrozumienie procesu kształtowania się cen opcji, metod ich wyceny i możliwości doboru ich parametrów są tak istotne dla menedżerów finansowych, którzy stosują aktywne podejście do zarządzania ryzykiem w przedsiębiorstwie lub instytucji.

Słowa kluczowe: zarządzanie ryzykiem, derywaty, opcje, funkcja wypłaty, premia opcyjna, hedżowanie.

DOI: $10.7862 /$ rz.2017.hss.46

Przestano do redakcji: marzec $2017 \mathrm{r}$.

Przyjęto do druku: wrzesień 2017 r. 
